\title{
Surgieal Management of Large Villous Tumours
}

Imane Toughrai, Ihsan Mellouki', Imane Kamaoui' ${ }^{2}$ Said Ait Laalim, Karim Ibn Majdoub, Khalid Mazaz, Adil Ibrahimi'

From the Department of General Surgery, Gastroenterology' and Radiology², Faculty Hospital of Fes, Morocco.

\begin{abstract}
:
Villous tumours of digestive tract are rare and pre malignant lesions. Their discovery is, usually, fortuitous during an endoscopic examination. The removal of villous tumours must be complete, because of their recurrence and degeneration potential. Large villous tumors are still a limitation for endoscopic removal and need a surgical management. High morbidity and mortality rate and functional disorders of radical surgery have led to an increasing interest in many other procedures which can expose to recurrence risk especially in rectal localization. We review the literature and report our experience in managing two cases of large villous tumours in two different localizations.
\end{abstract}

Key words: Rectal Neoplasms, Rectum, Endoscopy, Gastrointestinal Tract.

\section{Introduction}

Endoscopic approach is the first line of treatment in villous tumour. However, the size and the location can restrict the use of endoscopic removal. Surgery is, then, indicated but the choice between radical surgery and minimally invasive surgery can be difficult. High morbidity and mortality rate and functional disorders of radical surgery have led to an increasing interest in many other procedures which can expose to recurrence risk especially in rectal localization. We review the literature and report our experience in managing two cases of voluminous villous tumour.

\section{Case Reports}

\section{Case 1:}

A 46 year-old woman with a history of a mental retardation was hospitalized for a prolapsed mass through the anus. Her clinical examination was unremarkable with a good hemodynamic and general condition. Digital rectal examination revealed a voluminous process at $3 \mathrm{~cm}$ from the anal orifice. Laboratory tests didn't show any abnormalities. The rectoscopy found a large sessile and polypoid tumour [Fig.1]. A complementary

\section{Corresponding Author: Dr. Imane Toughrai}

Email: toughiman@hotmail.com

Received: November 23, 2012 | Accepted: January 1, 2013 | Published Online: January 15, 2013

This is an Open Access article distributed under the terms of the Creative Commons Attribution License (creativecommons.org/licenses/by/3.0)

Conflict of interest: None declared | Source of funding: Nil | DOl: http://dx.doi.org/10.17659/01.2013.0006 
colonoscopy failed to identify any associated carcinomatous or adenomatous lesion. Computed tomography imaging showed a giant anorectal tumour without any distant or loco regional extension [Fig.2]. Endoscopic and imaging aspects were typical of a villous tumour. In view of lesion size and difficulties encountered during endoscopic total excision, surgical excision was planned. The patient underwent a transanal resection using an endorectal traction flap. The post operative period was uneventful and the patient was discharged two days later. The pathologic examination concluded to a villous tumour with highly multifocal dysplasia. The resection margins were positive. The patient had a recurrence 8 months later and was, again, operated using the same technique. During a follow up of 2 years, with a digital and endoscopic rectal exploration every 3 months, there was no evidence of recurrence in our patient.

\section{Case 2:}

A 50 year-old woman was admitted for recurrent episode of hematemasis. An oesogastroduodenoscopy showed a large bleeding and polypoid mass of the gastric fundus [Fig.3]. The computed tomography investigation demonstrated a large lobulated gastric tumour with a central vascular axis, hypodense and cerebroid appearance. There was no evidence of local invasion or suspect distant lesion [Fig.4].

The patient underwent a total gastrectomy plus Roux-en-y oesophagojejunostomy. The pathological examination of the specimen confirmed the diagnosis of gastric villous tumour. The margins of resection were negative.

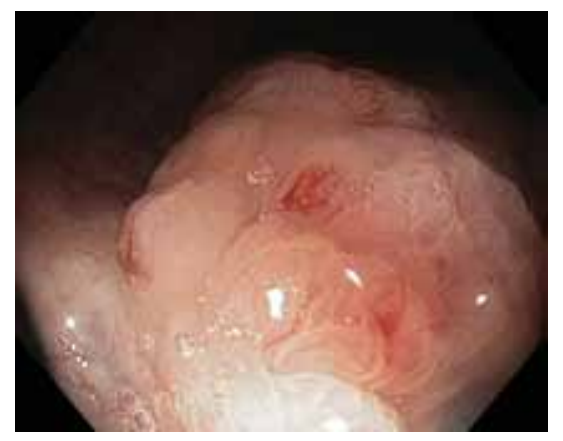

Fig.1: Endoscopic view of a rectal villous tumor.

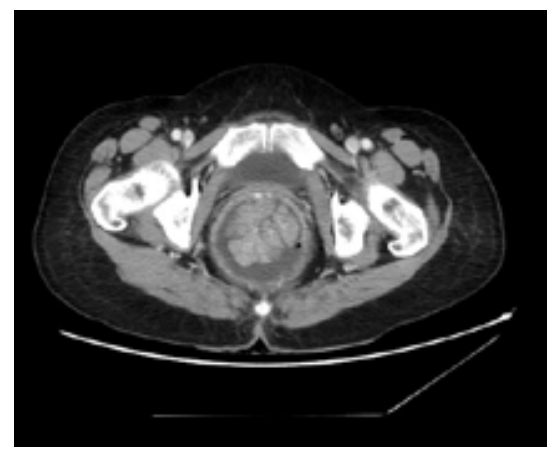

Fig.2: CT scan view which shows a giant and cerebroid anorectal tumor. 


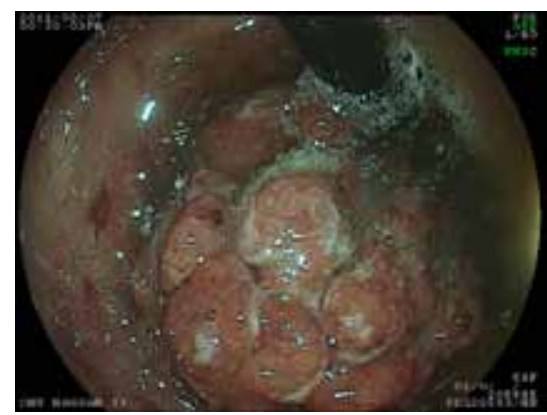

Fig.3: Endoscopic view of a villous tumor of the gastric fundus.

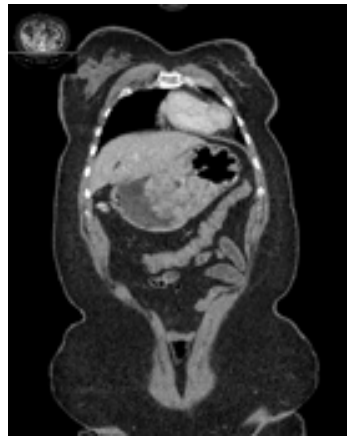

Fig.4: A large lobulated gastric tumor demonstrated in the CT scan.

The patient developed a thrombophlebitis treated by anti-coagulation. She was discharged in the tenth postoperative day.

\section{Discussion}

Villous tumours of digestive tract are rare and pre malignant lesions. They are defined macroscopically as large sessile process with villous architecture [1, 2]. Histologically, they are, most often, villous adenomas [1]. Rectal and colonic villous tumours are the most reported in literature [1-9]. Their potential for malignant degeneration is estimated to 40 to $50 \%$ of cases. It depends on their size and the degree of dysplasia which are correlated [10-14].

In general, the discovery of these tumours is fortuitous during an endoscopic examination. The clinical presentation is not specific as an abdominal pain, diarrhoea or anaemia. Large tumour may cause obstructive symptoms. Secreting lesions may be revealed by a massive water and electrolyte depletion as a result of prostaglandin secretion. This can lead to a Mckittrick-Wheelock syndrome with acute renal failure, metabolic and hemodynamic troubles $[9,15]$. Typically, haemorrhage is induced by the examination or after biopsy. In our patient, tumour was revealed by hematemesis in one case and by a tumour protrusion through the anus in the other which can be attributed to their size.

The diagnosis can be established at the endoscopic investigations with pathologic examination of the biopsy 
specimen. Magnetic resonance (MR) and endorectal ultrasound (ERUS) are more accurate to evaluate parietal and sphincter infiltration of rectal tumour than computed tomography imaging $[9,12]$. Worrell et al, in their meta-analysis, recommend the use of a biopsy within an ERUS examination in order to decrease the number of misdiagnosed local degeneration [16].

Because of their recurrence and degeneration potential, the removal of villous tumours must be complete and en-bloc with free margins. Successful endoscopic resection of pedunculated adenoma is possible. Sessile lesion requires endoscopic mucosal resection (EMR) which can provide an en-bloc specimen $[14,17,18]$. Endoscopic sub mucosal dissection (ESD) is a new technique which can remove larger lesion. This is possible when the lesion is limited to the mucosa [18]. ESD can be used in stomach and colorectum. However, it seems to be safer in gastric localization because of the thickness of the wall and the lumen large compared with the colorectum [18]. Photodynamic therapy as the YAG laser makes histological evaluation impossible. It must be reserved for patients with high surgical risk and who have residual or recurrent lesion after endoscopic resection [6].

Large villous tumors are still a limitation for endoscopic removal and need a surgical management. Surgical strategy depends on the size and the site of the tumour. Rectal villous tumour require radical surgery includes proctectomy with sphincter preservation or abdominoperineal resection with permanent iliac or perineal stoma. It is usually associated with peri-operative mortality, sexual and urinary morbidity and functional disorders.

The conventional local transanal approach consists on a full-thickness excision using the traction flap technique. It's classically indicated for tumour located between 5 and $8 \mathrm{~cm}$ from the anal verge [12,19]. In our patient, the tumour size was greater than $4 \mathrm{~cm}$ which is a limitation for this technique in view of risk of incomplete or piecemeal resection [12]. The lesion was further located at the ano rectal junction and required an abdomino perineal resection with permanent stoma. Considering her mental condition and the difficulties to manage functional disorders, we choose a conventional transanal procedure with a strict follow up protocol.

For the mid and upper rectum, Koutarou et al proposed the use of an originally designed retractor with threebladed device and a cylinder. It improves the exposure of higher lesion and permits the shortening and the invagination of the rectum. The invaginated rectum is, then, excised and anastomosed by a stapler application [19].

Transanal endoscopic microsurgery (TEM) is, also, a good alternative compared with radical surgery in mid and upper rectal lesions. But it is technically complex and requires long time training and expansive material [20]. It uses a specifically designed rectoscope which is connected to a three-dimensioned binocular system with a continuous insufflation of the rectum. This gives an enlarged intra rectal space with a magnification of the view. So the full-thickness and en-bloc excision is achieved with adequate resection margins around the lesion [21]. Sutures are required in anterior tumours which are lying above the peritoneal reflection in order to prevent rectal perforation [20-22]. Tumours at 16 to $20 \mathrm{~cm}$ from the anal verge were included in some studies [22,23]. TEM offers control equivalent to radical surgery. This procedure is still limited to specialised centres because of the high cost of instrumentation and the long learning curve [20,21].

A new local transanal approach was recently proposed using a single port trocar with conventional laparoscopic material which can be inserted in the anal canal [24]. This procedure is accessible to laparoscopic surgeons and 
seems to be safe and simple with lower cost compared with TEM [24]. Surgical management is less controversial in other localizations as in stomach colon or appendix. Segmental resection is, usually, sufficient in large lesions since the removal has been complete [3]. In our second patient we had to perform a total gastrectomy because of the big size of the tumour and its localization in the gastric fundus.

\section{Conclusion}

Because of their tendency to recur and the possible malignant degeneration of residual lesion, total removal as a single piece with tumour free margins is mandatory in large villous tumours. The decision should be made considering the mortality and morbidity rates of radical surgery and the accessibility of the other surgical procedures.

Although the newly described techniques for rectal villous tumours offer good results with low rates of mortality and morbidity, they are still not widespread in all countries. In patient who refuses radical surgery or radical surgery cannot be performed, conventional transanal resection appears to be safe and effective if a strict follow up is performed.

\section{References}

1. Droy L, Kury S, Airaud F, Maury I, Cauchin E, Bezieau S et al. Hétérogénéité histopathologiques et moléculaires des tumeurs villeuses recto-sigmoidiennes. Annales de pathologie. 2011 ;31:135-136.

2. Merzouk M, El Alaoui EM, Moumen M, Biadillah MCH. Tumeurs villeuses rectales. Médecine du Maghreb. 1993;38:23-24.

3. Bodin R, Peycru T, Schartz A, Jarry J, PommierN, Durand-Dastes F. Tubulo villous adenoma of the appendix: A case report and review of the literature. Gastroentérologie clinique et biologique. 201 0;34:633-635.

4. Kawakami H, Kuwatani $M$, Onodera M, Aska M. Villous adenoma arising in choledochocele. Gastrointestinal endoscopy. 2007;66:1231-1232.

5. Delsol-Tahou M, Bellannée G, Trouette H, Jougon J, Combes $M$, Bernard PH et al. Polype tubulo-villeux ou dysplasie polypoide de l'oesophage: une observation. Annales de pathologie. 2002;22:1 24-126.

6. Saleem A, Kenneth K, Wang K, H. Baron T. Successful endoscopic treatment of intraductal extension of a villous adenoma with high-grade dysplasia, with 3-year follow-up. Gastrointestinal endoscopy. $2011 ; 74: 714-716$.

7. Chiang KH, Shau-Bin Chou A, Liu.YX, Lee CC, Yen PS, Ling CM et al. Intussusception of the appendix by a villous adenoma: A case report. European Journal of Radiology. 2005;56:75-77.

8. Stroppa I, Lionetti R, Andrei F, Cocco A, Farinon AM, Pallone F. Large villous adenoma of the appendix: A case treated with sequential endoscopic-minimal surgical technique Digestive and Liver Disease. 2009;41:450-452.

9. De Vargas Macciucca M, Casale A, Manganaro L, Floriani I, Fiore F et al. Rectal villous tumours: MR features and correlation with TRUS in the preoperative evaluation. European Journal of Radiology. 2010;73:329-333.

10. Risio M. The natural history of adenomas. Best Practice \& Research Clinical Gastroenterology. $2010 ; 24: 271-280$. 
11. Chen H, Lefferts JA, Schwab MC, Suriawinata AA, Tsongalis GJ. Correlation of polypoid colorectal adenocarcinoma with pre-existing adenomatous polyps and KRAS mutation. Cancer genetics. $2011 ; 204: 245-251$.

12. Bretagnol $F$, Panis $Y$. Comment prendre en charge une tumeur villeuse étendue du bas rectum? Gastroentérologie clinique et biologique. 2009;335:F101-F105.

13. Kelly PL, Lauwers GY. Gastric polyps and dysplasia. Diagnostic histopathology. 2010;17:50-61.

14. Lesur G. Polypes gastriques: les reconnaître, savoir lesquels enlever. Gastroentérologie clinique et biologique. 2009;33:233-239.

15. Pucci G, Rondelli F, Avenia N, Schillaci G. Acute renal failure and metabolic alkalosis in patient with colorectal villous adenoma (Mckittrick-Wheelock syndrome). Surgery 2012. (In press)

16. Worrell S, Horvath K, Blakemore T, Flum D. Endorectal ultrasound detection of focal carcinoma within rectal adenomas. The American Journal of Surgery. 2004;187:625-629.

17. Dumontier I, Poulet B, Carnot F, Barbier JP. Les tumeurs bénignes de l'estomac. EMC 1998. Gastroentérologie. 9-026-A-10.

18. Fujishiro M, Yahagi N, Kakushima N, Kodashima S, Ichinose M, Omata M. Successful endoscopic en bloc resection of a large laterally spreading tumour in the rectosigmoid junction by endoscopic submucosal dissection. Gastrointestinal Endoscopy. 2006;63:178-183.

19. Maeda K, Maruta M, Sato H, Hanai T, Masumori K, Matumoto M et al. Outcomes of novel transanal operation for selected tumours in the rectum. J Am Coll Surg. 2004;199:353-360.

20. Semana M, Bretagnola F, Guedib N, Maggioria L, Ferrona M, Panis Y. Transanal endoscopic microsurgery (TEM) for rectal tumour: The first French single-centre experience. Gastroentérologie clinique et biologique. 2010;34:488-493.

21. Asencio Arana F, Uribe Quintana N, Balciscueta Coltell Z, Rueda Alcárcel C, Ortiz Tarín I. Transanal endoscopic surgery with conventional laparoscopy materials: is it feasible. CIR ESP. $2011 ; 89: 101-105$.

22. Ferrer Marquez M, Reina Duarte A, Rubio Gil F, Belda Lozano R, Alvarez Garcia A, Blesa Sierra I. Indications and Results of Transanal Endoscopic Microsurgery in the Treatment of Rectal Tumours in a Consecutive Series of 52 Patients. CIR ESP $2011 ; 89: 505-510$.

23. Guerrieri $M$, Baldarelli $M$, Morino $M$, Trompetto $M$, Da Rold A, Selmi I et al. Transanal endoscopic microsurgery in rectal adenomas: experience of six Italian centres. Digestive and liver disease. 2006;38:202-207.

24. Cantero Cid R, García Pérez JC, González Elosua T, Lima Pinto F, Martínez Alegre J, Martín R et al. Transanal resection using a single port trocar: a new approach to notes. CIR ESP. 201 1;89:20-23. 